\title{
Chateaubriand réviseur et annotateur de ses cuvres, textes réunis par Patrizio Tucci
}

\section{Ida Merello}

\section{(2) OpenEdition}

1 Journals

\section{Édition électronique}

URL : http://journals.openedition.org/studifrancesi/5656

DOI : 10.4000/studifrancesi.5656

ISSN : 2427-5856

Éditeur

Rosenberg \& Sellier

\section{Édition imprimée}

Date de publication : 1 septembre 2011

Pagination : 421

ISSN : 0039-2944

\section{Référence électronique}

Ida Merello, "Chateaubriand réviseur et annotateur de ses œuvres, textes réunis par Patrizio Tucci », Studi Francesi [En ligne], 164 (LV | II) | 2011, mis en ligne le 30 novembre 2015, consulté le 13 janvier 2021. URL : http://journals.openedition.org/studifrancesi/5656 ; DOI : https://doi.org/10.4000/ studifrancesi.5656

Ce document a été généré automatiquement le 13 janvier 2021.

\section{(c)}

Studi Francesi è distribuita con Licenza Creative Commons Attribuzione - Non commerciale - Non opere derivate 4.0 Internazionale. 


\title{
Chateaubriand réviseur et annotateur de ses œuvres, textes réunis par Patrizio Tucci
}

\author{
Ida Merello
}

\section{RÉFÉRENCE}

Chateaubriand réviseur et annotateur de ses œuvres, textes réunis par PATRIZIO TUCCI, Paris, Champion 2010, 266 pp.

1 Ce volume réunit les actes du colloque qui s'est tenu à Padoue en décembre 2007. JeanClaude BERCHET (Le dernier avatar des "Euvres complètes": les "Mémoires d'outre-tombe", pp. 18-33) analyse la réutilisation que Chateaubriand fait de ses premières œuvres à l'intérieur des Mémoires d'outre-tombe: l'autocitation atteint le double but de mettre en valeur des morceaux dont il veut bien montrer l'importance et de les utiliser en tant que documents pour une mise en scène de lui-même face à l'histoire (et à l'histoire littéraire). Les Mémoires sont donc perçus comme le lieu en évolution perpétuelle où tout l'ouvrage de Chateaubriand est mis en perspective, lu et révisé. Piero tofFano (Retour sur les réécritures de la "Nuit chez les sauvages", pp. 35-45) écrit un commentaire comparatif qui prend en considération le dernier chapitre de l'Essai sur les révolutions (Nuit chez les sauvages d'Amérique) et le même morceau repris dans le Génie du Christianisme et dans les Mémoires d'Outre-tombe. Ce qui intéresse l'auteur est le changement de tonalité d'un passage à l'autre: la tonalité religieuse qui apparaît dans le Génie, où tout révèle la présence cachée de Dieu, la tonalité des Mémoires, où Chateaubriand installe son propre personnage dans l'histoire littéraire. Alain GUYOT ( $D u$ "Génie" primitif à "Atala": quelques réflexions sur les récritures de la "matière américaine", pp. 47-63) se penche sur les pages des éditions préoriginales du Génie retranchées de l'édition définitive mais publiées dans les đuvres complètes au t. XXXI. Il analyse ainsi les amendements stylistiques ou bien de syntaxe et de grammaire, s'arrêtant sur les 
passages de réorganisation et de renforcement des figures métaphoriques et montrant que l'auteur adapte le texte au passage d'un genre à l'autre. Jean-Marie Roulin (Le remploi des articles de presse: vers une écriture de l'actualité, pp.65-74) prend en considération les articles de presse de Chateaubriand, pour mettre en évidence leur qualité littéraire et leur rôle dans l'élaboration par la suite des textes de fictions. Il montre le travail d'actualisation auquel les articles sont soumis en rapport aux circonstances du moment. Jean-Paul CLÉMENT ("De Bonaparte et des Bourbons" et les "Réflexions politiques": Chateaubriand réviseur de ses œuvres politiques, pp.75-88) décrit l'évolution de l'attitude de l'écrivain à l'égard de Napoléon. Les premiers écrits sont soumis à révision pour atténuer les jugements négatifs et le mépris, jusqu'à une progressive réévaluation du grand personnage. Jean-Christophe CAVAluin ("Mémoires" de 1834 et "Mémoires" de 1847: deux [flamboyants] grands météores, pp. 89-101) explique un jeu de variantes dans les différentes versions des Mémoires à propos de la disparition de l'adjectif «flamboyant», dans laquelle il décèle une signification aux aspects symboliques très complexes.

2 Le volume contient deux autres sections, consacrées notamment aux "palimpsestes» et aux notes de l'auteur, dont il est impossible de faire état dans toute leur richesse foisonnante: la section «palimpsestes» accueille des interventions d'Aurelio PRINCIPATO, Fabienne BERCEGOL, Emmanuelle TABET, Patricio TUCCI, Emmanuelle BERVILLÉ; la section «contrepoint des notes» se nourrit des contributions de Marika PIVA, Philippe ANTOINE, Elisa GREGORI, Ivanna ROSI. Le volume est suivi d'un index des noms, établi par Elisa GREGORI, et d'un index des œuvres de Chateaubriand citées, dont il faut remercier Marika PIVA. 